\title{
A Dutch test with the NewProd-Model
}

\author{
J. J. A. M. Bronnenberg and M. L. van Engelen \\ Faculteit der bedrijfskunde, Universiteit Twente, Postbus 217 \\ 7500 AE Enschede, Netherlands.
}

\section{Abstract}

The paper contains a report of a test of Cooper's NewProd model for predicting success and failure of product development projects. Based on Canadian data, the model has been shown to make predictions which are $84 \%$ correct. Having reservations on the reliability and validity of the model on theoretical grounds, we set out to test it using data collected in the Netherlands.

Following Cooper's methodology, we selected 19 projects, which had already been marketed and of which 9 were clearcut successes and 10 clearcut failures. We also studied 9 additional projects, which had not yet been commercialised, as the basis for a future a priori test. The projects were given a product score according to Cooper's criteria, and predictions compared with the actual experience. Eightyfour percent were correctly classified, as in Cooper's work. From a practical point of view however the variance was too large to allow the predictions from NewProd to be used with confidence to predict outcomes unless they are clearcut.

We believe that the drawback of the methodology is that the product score is a simple combination of the various factors involved. No allowance is made for the possibility that one factor alone might be responsible for failure. We have therefore introduced the concept of a threshold value for each factor. A project for which any factor falls below this value will be deemed a failure. Based on a very limited sample of 19 cases an improvement of reliability was made to $95 \%$ of 18 out of 19 products correctly classified. The NewProd concept so modified is being applied to the sample of 9 as yet uncompleted projects, and its predictions will eventually be compared with actual outcomes.

\section{INTRODUCTION}

The search for models which can simplify and support complex management decisions is useful and necessary. It may be expected that the trend toward more and more accessible data will eventually result in even more complex decisions. Models can be useful in reducing data to compact and comprehensive information, useful for decision making.

In this paper the decision involves the allocation of resources to new domestic developments, which should be based on information from all relevant functions in the corporation. Modelling this information allows comparing and systemizing information very quickly.

The article takes a closer look at a model, called NewProd, that was developed to select new product proposals. The model was applied to Dutch corporations to test its usefulness and reliability. The research also explored the way the model was constructed and its strengths and weaknesses.

The NewProd model (Cooper 1981, 1985) is basically a tool to compare and reduce complex information from various people about a new product development project. Based on this information, a prediction is made about a project's outcome in terms of success and failure. One of the key features (and a very strong qualitative point of the model) is that the opinions of people who have a major stake in a project are measured and compared in a quick and clear way. The model produces a very clear and systematic document for further qualitative discussions. The main point of this manuscript, however, is not qualitative but rather the quantitative analyses of the model's performance. 
THE NEWPROD RESEARCH: A BRIEF DESCRIPTION.

NewProd is a screening model to help select ideas for new products. It actually classifies project proposals as commercial successes and failures after market-launch. Because the model is especially designed to screen project proposals, it will be used in an early stage of project development.

The implicit goal of the model is to save futile costs and means (in a broad sense), which eventually turn out to be allocated to failing products. Booz, Allen and Hamilton (1982) found that only 1 out of 7 project proposals will be a commercial success in the market. NewProd does not claim to improve the ratio of 1:7 (for it is not a model to generate good ideas for new products), but the model "speeds up" the process of finding that one successful product.

The model was developed by R.G. Cooper from empirical research in Canada. He gathered data from 103 corporations, which resulted in a sample of 102 clearcut successes and 93 clearcut failures. In each case 48 variables were measured on ranked scales. The scales of the variables are from 0 to 10 and indicate the degree of agreement on 48 statements in a questionnaire. The degree of success or failure of the projects was also measured. First of all a definition of success and failure was provided to eliminate different perceptions of 'commercial success or failure'. After that, managers of firms were asked to rate the degree of success of their projects (from a profitability point of view) on a $[-5, \ldots,+5]$ scale. Consequently a database was formed, containing 197 cases where the degree of success or failure was known and where the 48 variables hypothesised to explain success or failure were known. The data were gathered on an $a$ posteriori basis, meaning that products, already in the market, were brought into the research as if they were project proposals.

Factor analysis was used to reduce the 48 variables to 13 underlying dimensions, which, after varimax rotation accounted for $69.3 \%$ of the variance of the original variables (Cooper, 1981). Multiple regression analysis was used to examine the predictive power of the dimensions and to link them to the degree of success or failure. Eventually 8 dimensions entered the regression equation. In descending order of importance the dimensions, which appeared to be critical in a project's success and failure, are listed in Table 1.

The predicted degree of success and failure, which is called the 'Product Score', is calculated by summarizing the elements of the regression equation (Table 1) and a constant of 0.328 . These elements in turn are obtained by multiplying the regression coefficients and their respective factor scores.

A project with a product score of -5 to 0 indicates a project that is being predicted a failure, whereas a product score of 0 to +5 indicates a predicted success. The validation results of the Canadian research were determined by the cross split half method. The Canadian sample was randomly split into two halves and new regression models were developed for each of them. Next the data of the first sample were used to test the model developed from the other half and vice versa. The results were as shown in Table 2.

The results indicate that the model has an overall accuracy of $84 \%$ and that the model predicts failures better than successes.

\section{THE NEWPROD-MODEL: A FURTHER}

EXAMINATION.

One of the goals of the Dutch test was to evaluate the model theoretically, to get background information about how to interpret the analysis of the results of the model in the Dutch NewProd test. Our comments on the Canadian research are summarized below:

1. The Canadian research was performed on an a posteriori basis. This implies that information about project proposals was gathered after the commercial outcome was a fact. Both reliability and validity can be affected by this approach. Reliability bias can occur because of the time that elapsed between the idea stage of a project and the checkpoint of that project in the NewProd research, whereas bias in validity may occur because of the fact 
Table 1 Multiple Regression Results

\begin{tabular}{|c|c|c|c|}
\hline Factor name & $\begin{array}{l}\text { Regr. } \\
\text { coeff. }\end{array}$ & $\begin{array}{l}\text { Std. Regr, } \\
\text { coeff. }\end{array}$ & $\underset{\text { value }}{\mathrm{F}-}$ \\
\hline $\begin{array}{l}\text { Product Superiority \& Uniqueness } \\
\text { Overall Project/Co. Resource Comp. } \\
\text { Market need, growth and size } \\
\text { Economic Disadvantage of Project } \\
\text { Newness to the Firm } \\
\text { Techn. Resource Compatibility } \\
\text { Market Competitiveness } \\
\text { Product Customness/Specialisation }\end{array}$ & $\begin{array}{r}1.744 \\
1.138 \\
0.801 \\
-0.772 \\
-0.354 \\
0.342 \\
-0.301 \\
-0.225\end{array}$ & $\begin{array}{r}0.463 \\
0.307 \\
0.199 \\
-0.179 \\
-0.956 \\
0.088 \\
0.080 \\
-0.054\end{array}$ & $\begin{array}{r}68.7 \\
30.0 \\
12.5 \\
10.2 \\
2.9 \\
2.5 \\
2.0 \\
0.9\end{array}$ \\
\hline $\begin{array}{ll}\text { Constant } & =0.328 \\
R \wedge 2 & =0.420 \\
\text { Adj. } R \wedge 2 & =0.395 \\
\text { F(8.186) } & =16.83 \\
\text { St. Err. } & =2.73\end{array}$ & & & \\
\hline $\mathrm{PS}=1.744 \mathrm{PSU}+1.138 \mathrm{RC}+$ & +0.328 & & \\
\hline
\end{tabular}

Ref: See Cooper, 1981.

Table 2 Validation Results in Canada (")

\begin{tabular}{llll}
\hline \hline & $\begin{array}{c}\text { Actual } \\
\text { success }\end{array}$ & $\begin{array}{l}\text { Actual } \\
\text { failure }\end{array}$ & Total \\
\hline $\begin{array}{l}\text { Predicted } \\
\text { success }\end{array}$ & $\begin{array}{l}90^{*} \\
(82.6 \%)\end{array}$ & $\begin{array}{l}19 \\
(17.4 \%)\end{array}$ & 109 \\
$\begin{array}{l}\text { Predicted } \\
\text { failure }\end{array}$ & 12 & $\begin{array}{l}74^{*} \\
(86 \%)\end{array}$ & 86 \\
Total & $(14.0 \%)$ & 93 & 195 \\
\hline
\end{tabular}

(") Numbers are numbers of cases. Asterisks indicate correctly classified cases. Percentages (in parenthesis) are row percentages (add 100\% across a row) and indicate conditional probabilities, e.g. P(success/predicted success)

Ref. See Cooper, 1981

that the outcome of the project was known to the respondents.

2. The model is subjective. Both the rating of the variables and the project's individual degrees of success and failure are open to a certain extent of 'intuitive response'.

3. Mathematically, it is not correct to apply multiple regression analysis in this research. The MRA technique requires the product score to be normally distributed (Kendall, 1980). Because only clearcut successes and clearcut failures are taken into account, the distribution of the actual product score will very likely have two peaks (a negative one for failures and a positive one for successes) instead of one. Therefore the actual product score can not be normally distributed, although it should be pointed out that the original article acknowledged this fact, also noting that MRA is a very robust technique, even when some of the assumptions, e.g. normal distribution, are not quite adhered to.

4. The results of the validation of the model were extremely good. This is partly due to the fact that only clearcut successes 
and failures were taken into account. If, for instance, a typical clearcut success has a product score of 3.0 and a typical clearcut failure has a product score of -3.0 it is not so likely that they will be classified wrongly, since the model's standard error is 2.73 (Cooper, 1981). If the cases were product scores that were in the 'gray area' of the model, for instance between -2 and +2 , validation results could very well be less good than $84 \%$.

\section{THE DESIGN OF THE DUTCH NEWPROD TEST}

Given the doubts expressed above, the model's utility and ability to predict success and failure of new products was tested with new data.

In the Dutch project, NewProd was tested in nine corporations. Each corporation was asked to select three products. Each product met the following requirements:

* there were more than 3 persons with enough knowledge about the product to rate the variables in the questionnaire,

* the projects were all domestic developments and all relevant functions were within the corporation (i.e. no subcontractors licensed production, etc.),

* the commercial outcome of two products was known, and that one was a success and one a failure,

* the first two products had to be recent developments; in this case not older than 5 years, and

* the third product was yet to be introduced.

Eventually 28 projects were selected: 9 successes, 10 failures and 9 new projects. In 19 cases the ability to predict success and failure could be tested directly because the commercial outcome of these products was known (a posteriori basis). The outcome of the new products isn't known, therefore the remaining 9 projects will be evaluated in two years or when their commercial outcome is known. As a result of that this a priori test will not be presented here.

The sample of corporations contained both industry and consumer oriented firms. By the time of the Dutch test the NewProd model had been modified by Cooper with consumer data. In the Dutch test some consumer products were also admitted.

Broken down in industries, the sample looks like this

* chemical (industrial)

* chemical (consumer)

* electronics

* machinery/construction

* fabrics

* diary-foods

The participating firms gave information on 28 projects of which 19 were considered for a posteriori evaluation. Of these projects 4 were consumer oriented products, the remaining 15 were industrial goods and products.

The sample of corporations contained both industry and consumer oriented firms, ranging from dairy foods to heavy machinery. Before the actual testing of the model all the corporations were briefed in separate meetings. In these meetings project teams of at least three people with different backgrounds were put together. A typical project team consisted of five persons, with functions such as: project leader, marketing manager, production manager, R\&D manager and usually a sales person.

In plenary sessions, the questionnaires were filled in individually by the members of the project team. The members were not only asked to rate the variables in the questionnaire, but also to rate the product's profitability. The data concerning the product's profitability were used to assess the actual product score by taking the weighed mean of the ratings of the individual team members. A weight is the rated confidence each team member has, about their statement on the product's commercial outcome.

\section{LIMITATIONS IN THE DUTCH TEST}

The NewProd model test used a smaller number of projects than did the Canadian research, where 200 projects were taken into account. The most important limitation in 
Table 3 Validation Results in the Netherlands

\begin{tabular}{llll}
\hline \hline & $\begin{array}{c}\text { Actual } \\
\text { success }\end{array}$ & $\begin{array}{l}\text { Actual } \\
\text { failure }\end{array}$ & Total \\
\hline $\begin{array}{l}\text { Predicted } \\
\text { success }\end{array}$ & $\begin{array}{l}9^{*} \\
(75 \%)\end{array}$ & $\begin{array}{l}3 \\
(25 \%)\end{array}$ & 12 \\
$\begin{array}{l}\text { Predicted } \\
\text { failure }\end{array}$ & 0 & $7^{*}$ & 7 \\
Total & $(0 \%)$ & $(100 \%)$ & \\
\hline
\end{tabular}

(*) ... same as Table 2

the Dutch test is the small sample size. Only 19 projects from 9 firms could be evaluated. Furthermore the 19 projects were evaluated on an a posteriori basis, as in the original research. Finally the composition of the sample is not consistent with the Canadian sample.

Because of the limitations cited above, it is clear that one should not draw any statistical conclusions from the Dutch test and research. The test and its conclusions have a strong casuistic character.

On the other hand, it does not mean that the conclusions are of no value at all. The results of the research should be regarded tentatively.

\section{RESULTS OF THE DUTCH NEWPROD-TEST}

After the information on projects was gathered in the Netherlands, it was processed with the first version of the NewProd software. The software was distributed by Centre d'Innovation Industrièlle Montreal (CIIM). The predicted product scores were thus obtained by Canadian software.

\section{CLASSIFICATION RESULTS}

The predicted outcomes of the projects, in terms of success and failure, are compared with the actual outcomes. The criterion for the actual outcomes is the product score. The model should generate a negative product score for failing products and a positive product score for successful products. The results of the comparison of the predicted and actual outcomes are listed in Table 3.
These 'classification results' suggest the accuracy of the model was $84 \%$. This is calculated as:

\# cases correctly classified 16

$$
* 100 \%=\square^{*} 100 \%=84 \%
$$

\# cases 19

This outcome is the exact equivalent of the validation results in the Canadian research and the conclusion is therefore that it seems as if the model can actually classify ( $a$ posteriori) cases into commercial successes or failures with a very high accuracy.

\section{ANALYSIS OF THE PRODUCT SCORE}

Apart from comparing predicted and real outcomes of the projects in terms of success and failure, the predicted and actual product scores were also compared and analysed. (Table 4 and Figure 1).

Figure 1 is the graphic representation of the results in table 4. The horizontal axis represents the actual commercial outcome of a product, which was determined by taking the weighed mean of the rated opinions about a project's profitability. The continuum of 'total failure' to 'total success' is ranked between ' $-5^{\prime}$ and ' $+5^{\prime}$ ' 0 ' being the turnover-point. The vertical axis represents the predicted values of the product scores by the model. The middle diagonal is the line on which the points should constitute an 'ideal prediction'. The two other diagonals define an area around the ideal prediction line plus or minus one times the standard error. 
Table 4 Actual and predicted product scores in the Dutch test

\begin{tabular}{|c|c|c|c|c|c|c|c|}
\hline \multicolumn{4}{|c|}{ Successes } & \multicolumn{4}{|l|}{ Failures } \\
\hline Proj. Id. & Pred. Ps & Act. Ps & Err. & Proj. Id. & Pred. Ps & Act. Ps & Err. \\
\hline \#01 & 1.2 & 2.8 & -1.6 & \# 03 & -0.8 & -3.2 & 2.4 \\
\hline \#04 & 0.1 & 3.7 & -3.6 & \#05 & -1.0 & -3.3 & 2.3 \\
\hline \# 08 & 2.6 & 4.0 & -1.4 & \#07 & -0.8 & -3.0 & 2.2 \\
\hline \#12 & 2.1 & 2.4 & -0.3 & \# 11 & -0.7 & -4.5 & 3.8 \\
\hline$\# 15$ & 2.5 & 3.0 & -0.5 & \# 14 & 1.4 & -2.5 & 3.9 \\
\hline$\# 16$ & 2.2 & 3.1 & -0.9 & \# 17 & -0.3 & -1.7 & 1.4 \\
\hline$\# 20$ & 0.9 & 3.5 & -2.6 & $\# 21$ & 0.3 & -1.7 & 2.0 \\
\hline$\# 23$ & 0.8 & 3.6 & -2.8 & $\# 22$ & 1.8 & -0.5 & 2.3 \\
\hline \multirow[t]{2}{*}{$\# 27$} & 1.5 & 2.6 & -1.1 & $\# 25$ & -2.5 & -3.3 & 0.8 \\
\hline & & & & $\# 26$ & -2.0 & -2.8 & 0.8 \\
\hline
\end{tabular}

From Figure I we may conclude the following:

1. The figure shows 19 cases. The 16 cases in sectors $\mathrm{A}$ and $\mathrm{C}$ are correctly classified. The remaining cases in sector $\mathrm{B}$ are actual failures, being predicted as successes. No cases are found in sector D, so no actual successes have been predicted as failures.

2. Of the wrongly predicted cases only one deviates more than the standard error of the multiple regresssion equation of 2.73 .

3. One of the clearcut successes is predicted as a borderline case and deviates more than the standard error of the model.

4. The constellation of the points is very typical. The figure suggests that all actual successes are below the ideal prediction line, whereas all actual failures are above this line.

5. It was expected that the best-fitting line between the points would be the ideal prediction line, in formula: (predicted PS) $=($ actual PS)

Instead the best-fitting line is represented by:

$($ predicted PS $)=0.59($ actual PS $)+0.74$

To test the significance of the tendency of 'flat' prediction, two statistical tests were carried out, one on the sample of successful products and one the sample of failures. The predicted product score has a standard error of 2.73 (Cooper, 1981). Because of the fact that the Canadian research has a large sample size $(n=195)$, one may treat the predicted product score as Studentdistributed (Smith, 1971). Therefore it is proper to analyze the differences of actual and predicted product score with a simple T-test (Mendenhall, 1982) based on the Dutch sample. The results of these tests are listed in Table 5. In this test the mean error is tested under the null-hypothesis that the mean error is equal to 0 .

For both successes and failures, the model shows differences between reality and prediction of at least $90 \%$ significance. In the case of failures the model shows differences between reality and prediction of even $95 \%$ significance.

This does not affect the ability to classify projects into 'successes' or 'failures', as can be seen in Figure 1. However it will influence the prediction of the product score (which is actually the degree of success or failure) strongly. The conclusion would then be that one should be very careful to base decisions on the predicted degree of success or failure. Also the 'gray area' of the model will increase as a consequence of the actual prediction line being less steep than the ideal prediction line.

It should be stated here that Cooper (1985) also points out that the value of the product score is rather limited, and that the model has benefits in other areas. In the last part of this paper the major benefits of the model will be given more attention. 
Table 5 Results of a T-test on the mean error of the model for the sample of successes and fallures.

\begin{tabular}{|c|c|c|}
\hline & Successes & Failures \\
\hline Hypotheses & $\begin{array}{l}H_{0}: \mu(\mathrm{PSp}-\mathrm{PSa})=0 \\
H_{1}: \mu(\mathrm{PSp}-\mathrm{PSa})>0\end{array}$ & $\begin{array}{l}\mathrm{H}_{0}: \mu(\mathrm{PSp}-\mathrm{PSa})=0 \\
\mathrm{H}_{1}: \mu(\mathrm{PSp}-\mathrm{PSa})>0\end{array}$ \\
\hline Test values & $\begin{array}{l}m \text { (error) }=-1.64 \\
s \text { (error) }=2.73\end{array}$ & $\begin{array}{l}m \text { (error) }=2.19 \\
s(\text { error })=2.73\end{array}$ \\
\hline T-Statistic & $\begin{aligned} t & =\left(m-\mu_{02}\right) * \sqrt{n} / s \\
& =-1.64^{*} \sqrt{9 / 2.73} \\
& =1.78\end{aligned}$ & $\begin{aligned} t & =\left(m-\mu_{02}\right)^{*} \sqrt{n / s} \\
& =2.19^{*} \sqrt{ } 10 / 2.73 \\
& =2.53\end{aligned}$ \\
\hline $\begin{array}{l}\text { Rejection } \\
\text { Area }\end{array}$ & $\begin{array}{l}\text { one-sided, left, } \\
\quad \alpha=0.10,[-\infty,-1.40]\end{array}$ & $\begin{array}{l}\text { one-sided, right, } \\
\alpha=0.10,[1.38, \infty]\end{array}$ \\
\hline Result & $\begin{array}{l}\text { null hypothesis } \\
\text { rejected }\end{array}$ & $\begin{array}{l}\text { null hypothesis } \\
\text { rejected }\end{array}$ \\
\hline
\end{tabular}

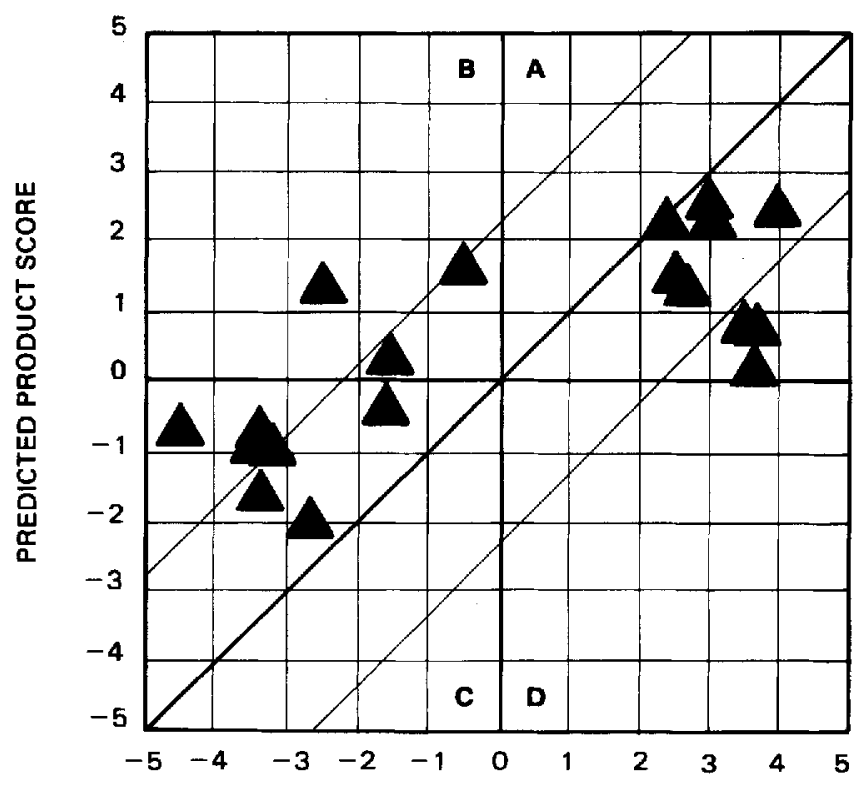

ACTUAL PRODUCT SCORE

Figure 1 Prediction characteristic of the Dutch test-project

\section{THE PROFILES OF SUCCESS AND FAILURE}

The product score is constructed out of the elements of the regression equation. One set of elements can be looked upon as a profile of a project's commercial strengths and weaknesses. The profile can be of great assistance to making 'go/no go' decisions and gives clear insight into a project's weak and strong points. 
A profile-element is actually the score on a relevant factor, weighed by the importance of the factor in the commercial outcome of a project.

The (mean) profiles for successes and failures were constructed and analysed to specify factors that may have been responsible for the classification errors. Figure 2 shows the mean profiles for successes and failures in the Dutch test. The 'mean successful project' possesses a product score of 1.54 , which is obtained by summarizing all the profile-elements plus the constant of the regression equation of 0.328 . The profile shows the correct pattern:

1. All the elements are positive, so the factors are all correlated (in the Dutch situation) in the same way as in the Canadian study,

2. Because the factors are ranked according to their importance of discriminating between success and failure, it is to be expected that the mean elements decrease as their rank numbers increase. This effect is clearly shown by the 'mean

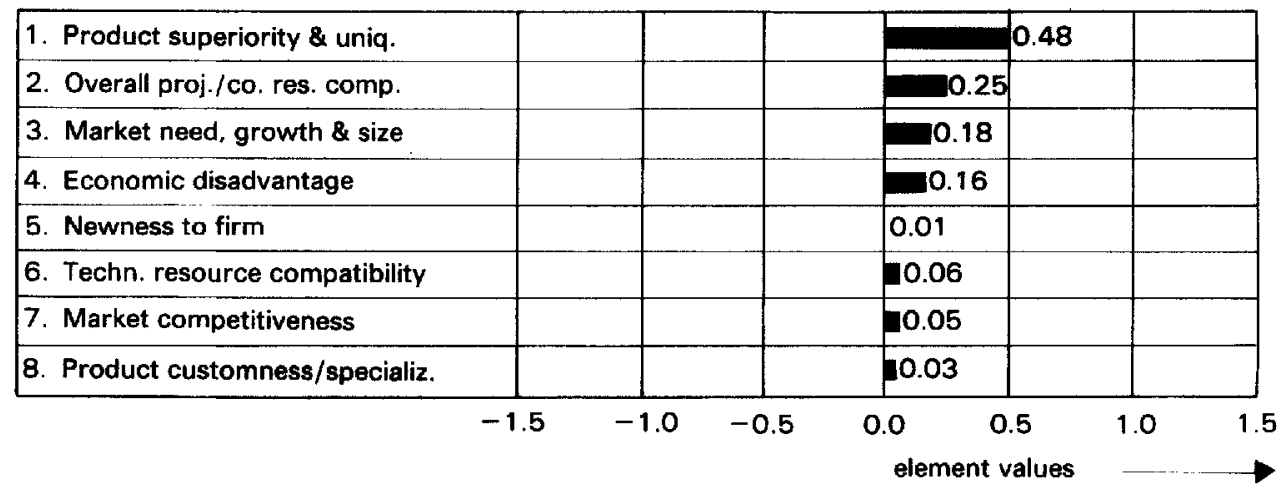

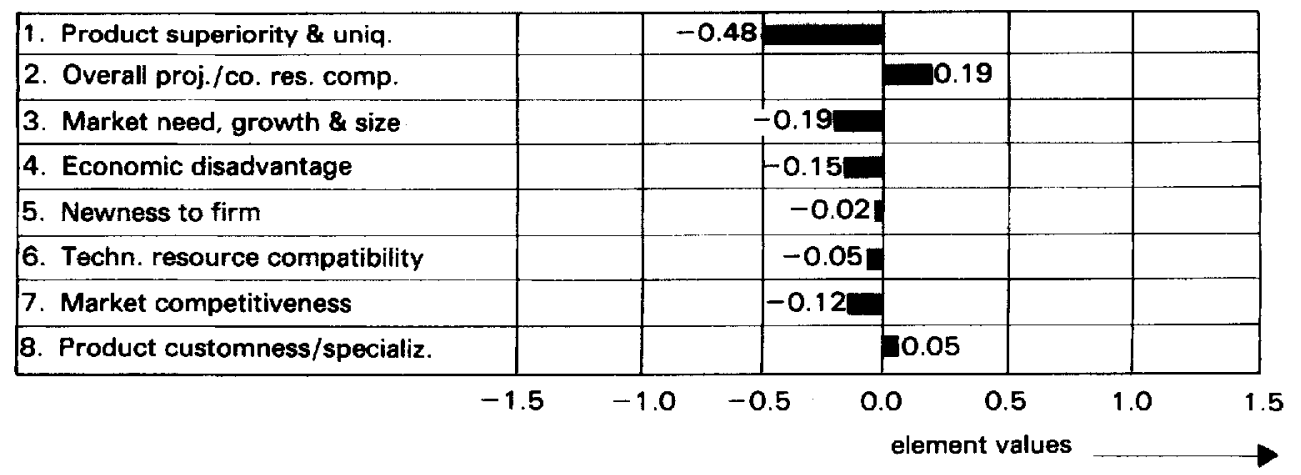

Figure 2 Mean profiles for the samples of successes and failures 
success' profile. The only exception would be the element of 'Newness to the firm', which looks actually too low.

In the case of the profile of the 'mean failure', strong deviations from the expected profile occur. The elements 'Overall Project/ Company Resource Compatibility' and 'Product Customness/Specialization' show positive values, where they should have negative ones. These elements don't have much discriminating power because they are positive for both successes and failures. This is very remarkable because the element of 'Overall Project/Company Resource Compatibility' turned out to be the second most-important in Canada. Because the elements of 'Overall Project/Company Resource Compatibility' and 'Product Customness/Specialization' have mean positive values in the cases of failures, failures are being predicted too positively in the Dutch test. Therefore prediction errors are more likely to occur for actual failures than for actual successes in the Dutch test.

\section{AN ADDITION TO THE NEWPROD MODEL:}

\section{The 'Threshold-Check'.}

The NewProd research points out that the commercial outcome of a new project can be described by 8 factors (Table 1). The product score, which is composed of these factors, is the criterion for the outcome of the prediction.

As a consequence of the statistical methods used, the model calculates the set of factors as a whole (the product score is namely the weighted sum of one set of factors). A major disadvantage of this approach is a loss of vital information and possibly very trivial classification errors.

If, for instance, a project scores very poorly on the factor 'Market need, size and growth', it will not have much of a chance (if any) to become a success. Nevertheless if all the other factors are positive (e.g. very good product, low price, high synergetic aspects for corporation, etc), the model may very well predict a clearcut success. In other words, in contrast to reality, the critical dimensions of success in the model form a set of elements which are mutually compensatory.

To overcome this problem, the prediction should be based on the individual elements of the project profile, as well as on the total sum of those elements. A technique which was developed at Twente University and which is called the 'Threshold-Check' is based on the following thought.

The elements in the profile all have to exceed a certain value (the threshold) to be a success. The underlying assumption is that success of a project is not possible if one or more of the 8 critical dimensions have a value which is 'too low'.

Strictly speaking two sets of thresholds are possible; one set of minimum values for successes and as Figure 3 suggests one set of maximum values for failures. Because of the fact that the individual dimensions of success and failure don't discriminate perfectly between success and failure, the two sets of thresholds will not be identical.

In this case we chose to estimate the thresholds for checking on successful projects for two reasons:

1. Both in Canada and in the Netherlands the model predicted failures better than successes. Therefore a check on the predicted successes would be of more use.

2. One can imagine that the case of a predicted success that turns out to be a failure is more harmful to a firm (development costs, market-launch, etc.) than the other way around. Therefore the extra check should be performed on predicted successes, rather than predicted failures.

Apart from these two reasons, common sense also indicates that checking predicted failures is not very useful. If a project is looked upon as a failure (because the total set of dimensions shows a negative image) the fact that one or a few dimensions show a positive value does not change the combination of dimensions as being insufficient for success.

In other words the assumption for a project to be successful is that

(a) the combination of dimensions has to show a positive value and 


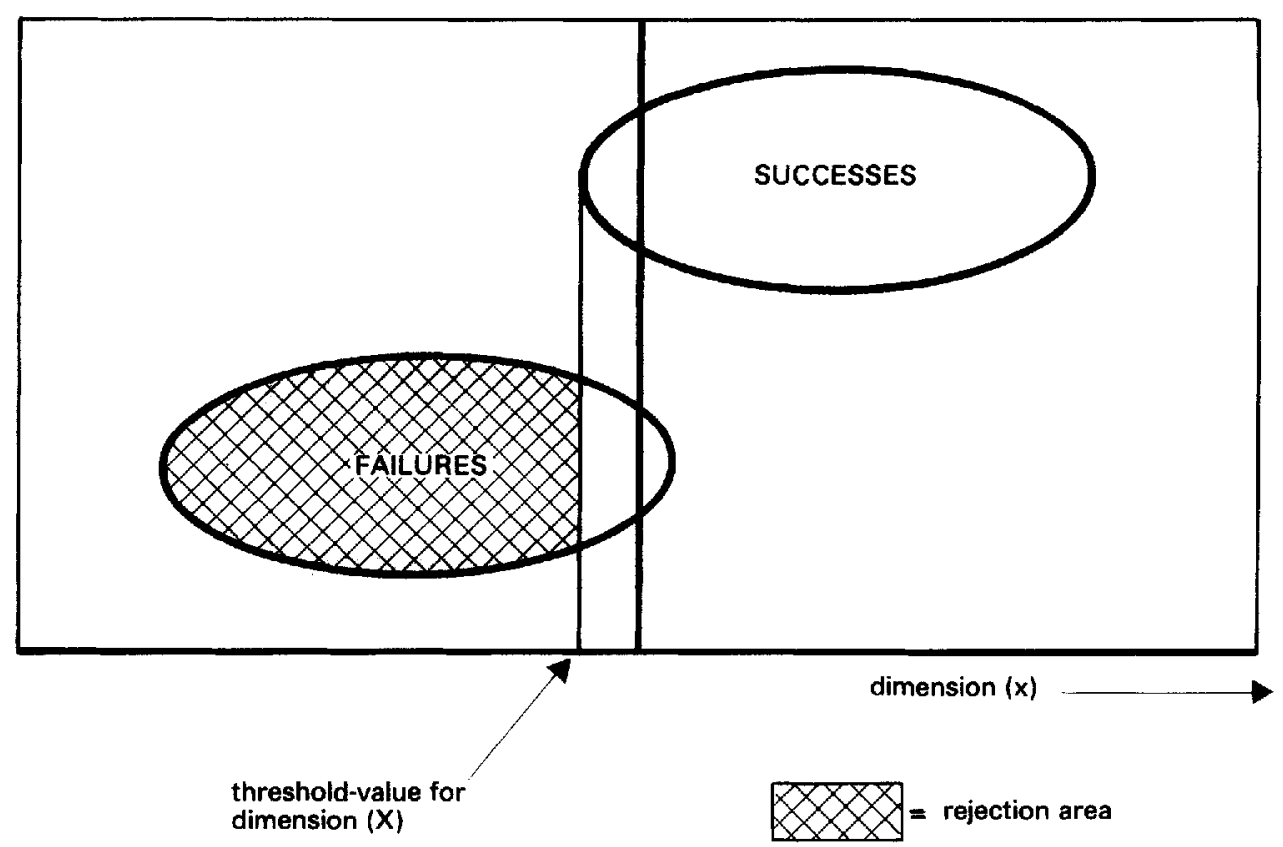

Figure 3 Univariate classification principle

(b) because the dimensions cannot compensate each other any individual dimension has to exceed a certain value (threshold) which is characteristic for each individual dimension.

One suggestion to estimate the thresholds could be as follows:

From a posteriori research, all values of the profile-elements are known, for the sample of successes and for the sample of failures. Figure 3 shows the common pattern, if one looks at the population of failures and successes. The value, under which empirically, no actual successes occur will be taken as the threshold for that dimension. A set of 8 thresholds will be the actual result: one threshold for each dimension.

The 'Threshold-Check' will only be used for predicted successes. If a project turns out to be predicted as a success, every element of the profile will be compared with its threshold value. If one or more of the values of the elements falls short of the threshold-value, the project will be treated as a predicted failure, as is shown in Figure 4.
The example is a predicted success, with a product score of 0.78 and is rejected because of the very poor market-dimension and because of the bad fit between the technical resources of the corporation and the technical needs of the project.

The 'Threshold-Check' is used in the Dutch test. The results are listed in Table 6. These results suggest an improvement of correct classification to $95 \%$ in the Dutch test. At least two comments can be made about this result. First of all, it will be necessary to do further research to find out more about the threshold values, because of the limited sample size. Second, in the Dutch test no classification errors were made in predicting failures. The 'Threshold-Check' has no effect on improving the reliability of predicted failures. Therefore it is likely that a reliability of $95 \%$ with the NewProd Model and the Threshold Check is an overestimation. In addition to this, the method of estimating the threshold values should possibly be reviewed in the future because it may lead to accepting hypothetical low values as thresholds. The result would be 
that the test will not reclassify cases; that is, will not work.

\section{BENEFITS OF USING THE MODEL}

This paper mainly highlighted the performance of the model in predicting a product's success or failure in commercial terms. Apart from this quantitative aspect the Dutch test indicated that the model has other qualities that, from the point of view of

Table 6 Classification results in the Netherlands after the Threshold Check.

\begin{tabular}{llll}
\hline \hline & $\begin{array}{c}\text { Actual } \\
\text { success }\end{array}$ & $\begin{array}{l}\text { Actual } \\
\text { failure }\end{array}$ & Total \\
\hline $\begin{array}{l}\text { Predicted } \\
\text { Success }\end{array}$ & $\begin{array}{l}9^{*} \\
(90 \%)\end{array}$ & $\begin{array}{l}1 \\
(10 \%)\end{array}$ & 10 \\
$\begin{array}{l}\text { Predicted } \\
\text { Failure }\end{array}$ & $\begin{array}{l}0 \\
(0 \%)\end{array}$ & $\begin{array}{l}9^{*} \\
(100 \%)\end{array}$ & 9 \\
Total & 9 & 10 & 19 \\
(") ... same as Table 2 & & \\
\hline
\end{tabular}

management, are at least as equally important as the benefit of prediction.

First of all, the model provides systematic measurement of opinions, lack of knowledge and information. Using the model forces a team of respondents to consider its opinion about the important aspects of the new product proposal, thus identifying critical areas of ignorance, uncertainties and risks (Cooper, 1985). Using the model also reveals areas of disagreement among the members of a venture team and leads to a meaningful and structured discussion.

The model identifies the project's strengths and weaknesses. If the product proposal is screened in an early development stage, weaknesses might still be adjustable to increase the project's commercial attractiveness.

Finally, using the model brings about some economic benefits as the allocation of means and efforts will be done in a more targeted and structured way toward winning projects.

In this respect the Dutch test showed that a systematic approach to new project selection is of great use to corporations, despite some quantitative imperfections.

\begin{tabular}{|c|c|c|c|c|}
\hline & & \multicolumn{2}{|r|}{ Element values } & \multirow{2}{*}{$\begin{array}{l}\text { Threshold values } \\
-0.47\end{array}$} \\
\hline 1. Product superiority $\&$ uniqueness & & & 0.49 & \\
\hline 2. Overall proj./co. resource comp. & & & 0.32 & -0.36 \\
\hline 3. Market need, growth and size & -1.10 & & & -0.40 \\
\hline 4. Economic disadvantage & & & 0.43 & -0.29 \\
\hline 5. Newness to firm & & & 0.33 & -0.30 \\
\hline 6. Techn. resource compatibility & & -0.22 & & -0.10 \\
\hline 7. Market competitiveness & & & 0.29 & -0.22 \\
\hline 8. Product Customness/Specialisation & & & 0.24 & -0.14 \\
\hline
\end{tabular}

Figure 4 Example of a trivial classification error $(P S=0.78)$

\section{ACKNOWLEDGMENT}

The NewProd research and model is used in this article by courtesy of Professor Robert G. Cooper, McMaster University, Hamilton, Ontario, Canada. We express our gratitude to him for making the Dutch NewProd test possible.

\section{REFERENCES}

Bock. R. D., (1975), Multivariate statistical methods in beha vioural research, McGraw-Hill, London.

Booze. Allen \& Hamilton. (1982). New Product Management for the 1980s, Booze, Allen \& Hamilton inc., New York.

Cooper. R, G., (1979), "The dimensions of industrial new product success and failure', Journal of Marketing 43:3 (Summer) pp. $93-103$.

Cooper, R. G., (1981), 'An empirically derived new product selection model', IEEE Transactions on Engineering Management, Vol. EM-8, No. 3, pp. 54-61. 
Cooper, R. G., (1984), 'The strategy-performance link in product innovation', $R \& D$ Management, 14:4, pp. 247-59.

Cooper, R. G., (1985), 'Selecting winning new product projects: Using the NewProd system', Journal of Product Innovation Management, No. 2:1, pp. 34-44.

Gorsuch, R. L., (1974), Factor Analysis, W. B. Saunders Company, London.

Heward, J. H., (1972), Business Control through Multiple Regression Analysis, Gower Press, London.

House, E. R., (1980), Evaluating with Validity, Sage Publications Ltd., London.
Kendall, M., (1981), Multivariate Analysis, second edition, Charles Griffin \& Co. Ltd., London.

Mendenhall, W., (1968), Introduction to Linear Models . . . . Wadsworth Publishing Company Inc., Belmont, California.

Mendenhall, W., (1982), Statistics for Management and Economics, Duxbury Press, Boston.

Smith, L. H., (1971), Statistical analysis for Business, Wadsworth Publishing Company, Belmont, California.

Wind. Y. (and others), (1981), New Product Forecasting, Part I. D C Heath \& Co., Lexington. 